\title{
A comparison of the poverty impact of transfers, taxes and market income across five OECD countries
}

\author{
Sami Bibi*and Jean-Yves Duclos ${ }^{\dagger}$
}

April 20, 2009

\begin{abstract}
This paper compares the poverty reduction impact of income sources, taxes and transfers across five OECD countries. Since the estimation of that impact can depend on the order in which the various income sources are introduced into the analysis, it is done by using the Shapley value. Estimates of the poverty reduction impact are presented in a normalized and un-normalized fashion, in order to take into into account the total as well as the per dollar impacts. The methodology is applied to data from the Luxembourg Income Study (LIS) database.
\end{abstract}

Keywords: Poverty reduction; Transfers; Taxes; Shapley value; OECD countries.

Classification JEL: D31; I32; I38.

This research is funded in part by Quebec's FQRSC. This work was also carried out with support from the Poverty and Economic Policy (PEP) Research Network, which is financed by the Government of Canada through the International Development Research Centre (IDRC) and the Canadian International Development Agency (CIDA), and by the Australian Agency for International Development (AusAID). We are grateful to Bernard Fortin, Guy Lacroix, Simon Langlois and François Blais for their helpful comments and suggestions.

* CIRPÉE, Pavillon DeSève, University of Laval, Quebec, Canada, G1K 7P4; email: sbibi@ecn.ulaval.ca; fax: 1-418-656-7798; phone: 1-418-656-2131 x13246

† Institut d'Anàlisi Econòmica (CSIC), Barcelona, Spain, and Département d'économique and CIRPÉE, Université Laval, Canada; email: jyves@ecn.ulaval.ca 


\section{Introduction}

Most OECD countries devote a substantial share of public resources to social transfers in order to redistribute income and reduce poverty. To assess the poverty effectiveness of such social transfers, it is usual to compute the change in poverty that they induce. In order to do this, a benchmark of pre-transfer income is first defined; the distributional impact of social transfers is then estimated as the fall in poverty estimated following the addition of the transfers, with or without the presence of behavioral responses. The poverty effectiveness of the transfers in alleviating poverty can also be computed per dollar of transfer.

A problem arises, however, in evaluating the impact of a set of social transfers that operate simultaneously. The order in which the transfers are ranked can indeed influence the estimates of the poverty reduction effect attributed to each individual transfer in the set. To illustrate this, consider the case of a country with two identical universal transfers. Assume that each transfer awards everyone a transfer equal to the poverty line (regardless of his/her income), so that no person is poor after the implementation of any of the two. If the benchmark income used to estimate the poverty effectiveness of one transfer includes the other transfer, none of the transfer will show any impact on poverty, albeit both lead to a total eradication of poverty when the other program is not included in the benchmark income. Since it usually arbitrary to prefer one order to the other, it would seem useful to think of a sharing rule that assigns each transfer a poverty impact that does not depend on the ranking of the various income sources. 1

The paper proposes such a rule by importing from cooperative game theory the use of the Shapley value. The procedure can be used for positive (transfers, earnings, capital income, etc.) or negative sources of income (such as income taxes). The paper also computes the effect of income sources across wide ranges of poverty lines and for broad classes of poverty indices in order to address the difficult of selecting "one" poverty line.

The paper then studies the poverty effects of a comparable set of social transfers that are in force in five OECD countries. Comparing national experiences on social transfers and poverty alleviation effects may provide useful policy guidance on alternative means of achieving social objectives. Social transfers differ both in terms of their scale and in terms of their distribution. Scale matters for the total change in poverty induced by a social transfer; distribution relates to the

\footnotetext{
${ }^{1}$ See for instance, Smeeding (2006), who computes the poverty impact of social insurance and social assistance benefits in 11 OECD countries without addressing this issue.
} 
effectiveness of poverty alleviation per dollar of transfer spent. Further, due to the size effect of the different income sources, their effectiveness in reducing poverty is measured using an indicator which weighs up the scale and the distribution of each income source.

The paper uses data on five OECD countries drawn from the Luxembourg Income Study (LIS) (http://www.lisproject.org), each with a recent 1999-2000 LIS database. They are Canada, United States, United Kingdom, Germany, and Sweden. The choice of these countries is based both on the availability of data and on the presence of similar national welfare programs across them.

The rest of the paper is structured as follows. Section 2 presents the poverty lines and the poverty measures. Section 3 describes the sharing rule used to estimate the scale and the distribution of the poverty impact of different social transfers. Section 4 applies the methodology to five OECD countries with similar tax and transfer systems. Section 5 concludes.

\section{Poverty}

How poverty is defined and measured is important for understanding poverty; it is also important for understanding the effectiveness of poverty alleviation programs. One influential definition of poverty is that it exists when one or more persons fall short of a level of consumption of goods and services deemed to constitute a reasonable minimum, either in some absolute sense or by the standards of a specific society Lipton and Ravallion 1995. This, however, usually involves the selection of one or a few arbitrary poverty lines. To guard against this degree of arbitrariness, the paper will compare the impact of income sources over wide ranges of poverty lines (see Section 4.2).

Note that this paper will use absolute poverty lines. With relative poverty lines, a social transfer that raises the incomes of all, but proportionally more those of the non-poor, may worsen poverty, albeit the absolute income of the poor has increased. Conversely, a progressive tax income that decreases everyone's income but proportionally more that of the non-poor, will reduce poverty, although the absolute income of the poor falls.

There is also the issue of which poverty index to use to estimate the effectiveness of redistributive policies. The most popular poverty index is the incidence of poverty, namely, the proportion of the population living with less than the poverty line. It has often been criticized (see for instance Sen (1976)) for only capturing the changes in the proportion of the population that is poor, and not capturing 
the changes in the well-being of the poor. Moreover, most anti-poverty welfare programs are often not designed to lift the poor entirely out of poverty; they do, however, purport to improve their living standards. This may not be adequately captured by the use of the poverty headcount.

Instead of just one index at one poverty line, we will use indices that are members of the popular (Foster, Greer, and Thorbecke 1984) (FGT) family of poverty indices over ranges of poverty lines. Let $z$ be a real poverty line. The FGT indices are defined as

$$
P_{\alpha}(y, z)=100 \int_{0}^{z}\left(\frac{z-x}{z}\right)^{\alpha} d F_{y}(x),
$$

where $F_{y}(x)$ is the cumulative distribution function of income $y . \alpha$ is a "poverty aversion" parameter; it captures the sensitivity of the index to changes in the distribution $^{2}$. As is well known, $P_{0}(y, z)$ is the incidence of poverty (the headcount ratio), $P_{1}(y, z)$ is the normalized average poverty gap measure (the "intensity" of poverty), and $P_{2}(y, z)$ is often described as an index of the "severity" of poverty - it weights poverty gaps by poverty gaps. For $\alpha>1, P_{\alpha}(y, z)$ is sensitive to the distribution of incomes among the poor, and when $\alpha$ becomes very large, $P_{\alpha}(y, z)$ approaches a Rawlsian measure (Rawls 1971).

\section{Impact of income sources on poverty}

\subsection{The Shapley value}

Consider $T$ income sources, including market income, transfers (social security, welfare, child benefits, etc.), and taxes. These income sources impact simultaneously on total income and individual poverty; we wish, however, to infer their separate contribution to total poverty reduction, in order for instance to determine which ones are more cost effective in redistributing income and reducing poverty.

To do this, we consider a rule based on the Shapley value. First, we need to specify a baseline situation, which we assume to be given by the distribution in which the income of everyone is nil. From (1), this means that initial poverty is equal to 100 regardless of the value of $\alpha$. Suppose now that the $T$ sources of income are ordered in a certain way. The poverty reduction due to the first source of income, market income say, is computed assuming that it is the unique

\footnotetext{
${ }^{2}$ See Zheng (1997) for a discussion of this.
} 
source of income; 100 minus the level of poverty with market income is then the contribution of market income to poverty alleviation. Next, the additional fall in poverty owing to the second source, social security say, is calculated by adding social security to market income. This pattern is repeated until total poverty reduction - achieved through total income - is allocated across the various income components.

The above is sometimes called an "incremental benefit" allocation procedure. It uses just one of the many possible orders in which income sources can be ranked. There is usually no ethical or other justification for a particular given ordering. An order also generally "overestimates" the contribution to overall poverty reduction of the income source that is included first in the ordering, and underestimates the contribution of the income source included last.

The Shapley value can help address such concerns. Let $Y$ be the set of all income sources $y_{i}, i=1, \ldots, T$, including negative ones such as income taxes ${ }^{3}$ Some income sources may be grouped to form a subset $S$ of $Y(S \subseteq Y)$. Define $S_{i}$ as a subset of $Y$ that does not include $y_{i}$, i.e., $S_{i} \subseteq Y \backslash\left\{y_{i}\right\}$, and $\pi_{\alpha}\left(S_{i}, z\right)$ as a characteristic function that satisfies $\pi_{\alpha}(\emptyset, z)=0$, where $\emptyset$ is the empty set. For a subset $S_{i}, \pi_{\alpha}\left(S_{i}, z\right)$ is the contribution of the welfare elements included in $S_{i}$ to total poverty reduction $\Delta P_{\alpha}(Y, z)=100-P_{\alpha}(Y, z)$, regardless of the effect that any $y_{i}$ external to $S_{i}$ may have. Since some elements of $S_{i}$ may contribute more to $\pi_{\alpha}\left(S_{i}, z\right)$ than others, the question arises as to how to distribute $\pi_{\alpha}\left(S_{i}, z\right)$ across the elements of $S_{i}$. To address this issue, several approaches have been suggested. The most popular one was introduced by Shapley (1953). It fulfills the following axioms.

Axiom 1 Efficiency: The overall poverty reduction generated by $Y$ is the sum of $\pi_{\alpha}\left(y_{i}, z\right)$, that is, the poverty reduction effected by each income source $i$ :

$$
\sum_{i=1}^{T} \pi_{\alpha}\left(y_{i}, z\right)=\Delta P_{\alpha}(Y, z)=100-P_{\alpha}(Y, z)=\pi_{\alpha}(Y, z) .
$$

Axiom 2 Symmetry: If $y_{i}$ and $y_{j}$ are symmetric (or perfectly substitutes), i.e., $\pi_{\alpha}\left(S_{i, j} \cup\left\{y_{i}\right\}, z\right)=\pi_{\alpha}\left(S_{i, j} \cup\left\{y_{j}\right\}, z\right)$, then:

$$
\pi_{\alpha}\left(y_{i}, z\right)=\pi_{\alpha}\left(y_{j}, z\right)
$$

\footnotetext{
${ }^{3}$ The value of these income sources will usually be adjusted for differences in individual needs and family composition, to be expressed in adult-equivalent income units.
} 
Axiom 3 Focus: Whenever $y_{i}$ does not change poverty, i.e., $\pi_{\alpha}\left(S_{i} \cup\left\{y_{i}\right\}, z\right)=$ $\pi_{\alpha}\left(S_{i}, z\right)$, then: $\underline{4}$

$$
\pi_{\alpha}\left(y_{i}, z\right)=0
$$

Axiom 4 Additivity: The cumulative poverty reduction generated by $S$ is the sum of the poverty reduction effected by each of its components. Or, phrased differently, $\forall S_{i, j} \subseteq Y \backslash\left\{y_{i}, y_{j}\right\}$, we have:

$$
\begin{aligned}
\pi_{\alpha}\left(S_{i, j} \cup\left\{y_{i}, y_{j}\right\}, z\right) & =\pi_{\alpha}\left(S_{i, j} \cup\left\{y_{i}\right\}, z\right)+\pi_{\alpha}\left(y_{j}, z\right) \\
& =\pi_{\alpha}\left(S_{i, j} \cup\left\{y_{j}\right\}, z\right)+\pi_{\alpha}\left(y_{i}, z\right) .
\end{aligned}
$$

The Shapley value induces an allocation rule $\pi_{\alpha}($.$) that allocates to each in-$ come source $y_{i}$ a weighted mean of the source's marginal (incremental) contribution to overall poverty reduction. It is the only allocation rule that satisfies the axioms listed above. The poverty reduction that $y_{i}$ gets with the characteristic function $\pi_{\alpha}($.$) is:$

$$
\pi_{\alpha}\left(y_{i}, z\right)=\frac{1}{2^{(T-1) !}} \sum_{R}\left[P_{\alpha}\left(S_{i}^{R} \cup\left\{y_{i}\right\}, z\right)-P_{\alpha}\left(S_{i}^{R}, z\right)\right]
$$

where $R$ crosses the $2^{(T-1) !}$ possible permutations of $Y$ and $S_{i}^{R} \subseteq Y \backslash\left\{y_{i}\right\}$ is the subset of income sources preceding $y_{i}$ within the order $R$. Equation (6) clearly shows that the contribution of an income source $y_{i}$ to overall poverty reduction is obtained by averaging its marginal contribution over all the possible different permutations $S_{i}^{R}$ from which $\pi_{\alpha}\left(y_{i}, z\right)$ can be computed.

\subsection{The poverty effectiveness of income sources}

We can think of the poverty effectiveness of a social transfer as depending both upon the poverty change it yields and the size of the budgetary cost that it generates. $\frac{5}{5}$ Indeed, for policy purposes, it is important to take into account both the "benefit" and the "cost" of the use of social transfers for distributive purposes.

To integrate the cost and the benefit of redistributive transfers, we may simply divide the poverty impact of an income source by the size of that source. Let $y_{i}^{*}$

\footnotetext{
${ }^{4}$ This is the well-known "dummy" axiom in cooperative game theory.

${ }^{5}$ This distinction is not always made; see for instance Makdissi, Therrien, and Wodon (2006) and Smeeding (2006) for comparative studies of the poverty effect of redistributive transfers in Canada and United States.
} 
be income from source $i,(i=1, \ldots, T){ }^{6}$ Then, the average of $y_{i}^{*}$ expressed as a percentage of the absolute poverty line, $z$, is:

$$
\bar{y}_{i}=\frac{100}{z} \int_{0}^{+\infty} y_{i}^{*} d F\left(y_{i}^{*}\right),
$$

where $F\left(y_{i}^{*}\right)$ is the distribution function of income source $y_{i}^{*}$. The ratio of $\pi_{\alpha}\left(y_{i}, z\right)$ to $\bar{y}_{i}$ yields $\Gamma_{\alpha}\left(y_{i}, z\right)$, the poverty impact of income source $i$ for a value of $\bar{y}_{i}$ equal to the poverty line:

$$
\Gamma_{\alpha}\left(y_{i}, z\right)=100 \delta \frac{\pi_{\alpha}\left(y_{i}, z\right)}{\bar{y}_{i}}
$$

where $\delta=1$ or -1 according to whether the income source $i$ is positive or negative.

Comparing $\Gamma_{\alpha}\left(y_{i}, z\right)$ across $i$ can help assess which transfers are most effective in reducing poverty per dollar spent, or which taxes are least costly in terms of poverty aggravation per dollar generated. ${ }^{7}$ Whenever $\Gamma_{\alpha}\left(y_{i}, z\right)>\Gamma_{\alpha}\left(y_{j}, z\right)$, each dollar spent on program $i$ reduces poverty more on average than that spent on program $j$.

\section{The poverty effectiveness of transfers, taxes and market income across some OECD countries}

The methodology presented above is illustrated using data from the Luxembourg Income Study (LIS) for Canada (CA), United States (US), United Kingdom (UK), Germany (DE), and Sweden (SE). For four of these countries, a (relatively) recent 2000 LIS database is available (1999 for the UK). These countries also have relatively similar tax and transfer systems that feature: ${ }^{.}$

1. Market Income (MI);

2. Old-age Benefits (OB);

3. Child Benefits (CB);

\footnotetext{
${ }^{6}$ This will usually be income per person, unlike $y_{i}$, which would usually be adult-equivalent income.

${ }^{7}$ If $y_{i}$ stands for a tax, $\Gamma_{\alpha}\left(y_{i}, z\right)$ measures the poverty increase per dollar of tax raised from $i$.

${ }^{8} \mathrm{~A}$ detailed content of some of these income sources can be found in Table 1
} 
4. Unemployment Benefits (UB);

5. Social Assistance and Insurance (SAI);

6. Other Income Sources (OS);

7. Income Taxes (IT) ;

8. Payroll Taxes (PT);

9. Other Direct Taxes (OT);

10. Net Income (NI).

To adjust for differences in household composition, we use the OECD-modified equivalence scale proposed by Hagenaars, de Vos, and Zaidi (1994) that assigns a weight of 1 to the household head, of 0.5 to each additional adult, and of 0.3 to each child who is less than 14 years old. To compare poverty across countries, we need a poverty line that represents the same purchasing power across the retained countries. For this, we first select the US official (absolute) poverty line and convert it for other countries into specific (absolute) poverty standards using the purchasing power parities (PPP) found in OECD (2005).

Tables 2 and 3 show some descriptive statistics related to the PPP, the absolute poverty lines in domestic currencies, and the mean of the different income sources across the countries. All of the statistics presented in Table 3 are expressed in percentage of the equivalent of the US official poverty line.

As one may expect, Table 3 shows that market income is the most important income source in the five countries. It ranges from 225 percent of the poverty line $(z)$ in the US to 140 percent of the same poverty standard in Sweden. Market income is followed by old-age benefits, which range from roughly 29 percent of $z$ in Germany to 11 percent in United Kingdom. The importance of the other positive income sources varies from one country to another. For instance, social assistance and insurance (beyond unemployment benefits) range from 18 percent of $z$ in Sweden to 5.1 percent in Canada. Sweden and Germany devote by far the highest absolute effort in dollar terms in social transfers, while the United states and, to a lesser extent, Canada spend the least. The united States devotes roughly 10 percent of its total market income in social transfers; this corresponds to roughly half the share of market income spent for the same purpose in the UK, and to about a third of the effort made in Sweden and Germany. Somewhat unsurprisingly, the tax burden is highest in both absolute and relative terms in 
Sweden and Germany, and is lowest in relative terms in United Kingdom, Canada and United States.

\subsection{Poverty impact}

The impact of the different income sources on poverty incidence and deficit, $\pi_{0}\left(y_{i}, z\right)$ and $\pi_{1}\left(y_{i}, z\right)$, is displayed in Tables 4 and 5, respectively. As expected, the poverty impact by income source is largely correlated with the share of the source in total income. Thus, the largest income source, market income, contributes most to lowering the incidence and the deficit of poverty, whereas several social transfers contribute absolutely little to overall poverty reduction. With their $\pi_{\alpha}\left(y_{i}, z\right)$ varying between -5 percent and -0.4 percent, the different taxes do not seem to worsen significantly either the incidence or the deficit of poverty. In any case, their negative impact is largely offset by the important positive effects of the social transfers.

A higher poverty reduction impact for market income is also naturally observed in those countries where market income is highest, namely, Canada and the US. Despite a higher average level of market income in the US, Tables 4 and 5 show roughly the same reduction in the incidence and in the deficit of poverty in Canada. This suggests (as will be confirmed below) a higher poverty effectiveness of market income in Canada than in the US.

Estimates of poverty effectiveness are shown in the last five columns of Table 4 for the incidence of poverty, i.e, $\Gamma_{0}\left(y_{i}, z\right)$, and in the last five columns of Table 5 for the deficit of poverty, $\Gamma_{1}\left(y_{i}, z\right)$. Both of these tables show that the poverty effectiveness of income sources is weakly correlated with the size of the sources. Sweden for instance, which is the poorest country in terms of market income (see Table 3), performs best in reducing the incidence and the deficit of poverty per dollar of market income. Sweden is followed by the UK, Germany and Canada, which all show poverty effectiveness indices that are not statistically different from each other, with the US lagging statistically behind.

Social transfers are sometimes more cost-effective than market income in reducing the incidence of poverty. This may seem surprising given that social transfers are usually designed and targeted to reduce poverty. Social transfers are, however, always more cost-effective in reducing the deficit of poverty.

To understand why this is so, consider Figure 1, which shows the case of one individual with two possible distributions of two income sources, $y_{1}$ and $y_{2}$. We can think of these two distributions $A$ and $B$ as two hypothetical distributions of market income $\left(y_{1}\right)$ and social transfers $\left(y_{2}\right)$. At point $A$, the individual receives a 
level of market income $y_{1}$ that is just lower than the poverty line $(z)$ and a transfer $y_{2}$ that is much less important than $y_{1}$. Since none of these income sources alone is sufficient to escape poverty, one finds (using (6)) that $\pi_{0}\left(y_{1}, z\right)=\pi_{0}\left(y_{2}, z\right)=50 \stackrel{9}{ }$ If, however, $y_{1}$ is increased marginally so that it just exceeds $z$ with $y_{2}$ remaining unchanged, as shown by point $B$ on Figure 1 , then both $\pi_{0}\left(y_{1}, z\right)$ and $\Gamma_{0}\left(y_{1}, z\right)$ jump discretely, and $\pi_{0}\left(y_{2}, z\right)$ and $\Gamma_{0}\left(y_{2}, z\right)$ both fall discretely to zero. Hence, if social transfers are not quite enough on their own to bring people out of poverty, they may be judged not to be cost-effective in terms of poverty headcount alleviation. This also suggests that measures of the poverty effectiveness of income sources based on the poverty headcount can be quite sensitive to small changes in the sizes of the sources. Finally, measures of poverty effectiveness based on the poverty headcount can also be sensitive to the choice of the poverty line. On Figure 1, increasing the poverty line above the level of $y_{1}$ at $B$ would lead to $\pi_{0}\left(y_{1}, z\right)=\pi_{0}\left(y_{2}, z\right)=50$ at point $B$.

Most social transfers (recall Table 1) in OECD countries are indeed not designed to bring on their own individuals completely out of poverty; they are rather aimed at alleviating their individual poverty gap. As a result, using the headcountbased $\Gamma_{0}\left(y_{i}, z\right)$ can fail to assess properly the achievement of poverty objectives. It may be better to use $\Gamma_{1}\left(y_{i}, z\right)$ and think instead in terms of alleviating the poverty deficit.

The effect of doing this can again be understood from Figure 1. On Figure 1 , $\pi_{1}\left(y_{1}, z\right)$ and $\pi_{1}\left(y_{2}, z\right)$ are proportional to $y_{1}$ and $y_{2}$ at point $A$, and we therefore have that $\Gamma_{1}\left(y_{1}, z\right)=\Gamma_{1}\left(y_{2}, z\right)$ at that point. The movement from $A$ to $B$ increases $\pi_{1}\left(y_{1}, z\right)$ marginally, but not discretely, and so $\pi_{1}\left(y_{2}, z\right), \Gamma_{1}\left(y_{1}, z\right)$ and $\Gamma_{1}\left(y_{2}, z\right)$ do not jump either. Measures of poverty effectiveness based on the poverty deficit are therefore much less sensitive to changes in the sizes of income sources and to the choice of the poverty line than measures of poverty effectiveness based on the poverty headcount. They are also better at capturing the effectiveness of policies that are not necessarily designed to bring individuals completely out of poverty.

Coming back to Table 5, we find that $\Gamma_{1}\left(y_{i}, z\right)$ for child benefits in Canada and for social assistance and insurance in the UK is particularly large, suggesting that these transfers display substantial poverty effectiveness. The various taxes in the UK, United Germany and Canada impact little the poor relative to their sizes. This suggest that the tax system of these countries succeeds better than the US and Sweden in not burdening the poor with taxes.

\footnotetext{
${ }^{9}$ Since $y_{2}<y_{1}$ while $\pi_{0}\left(y_{1}, z\right)=\pi_{0}\left(y_{2}, z\right)$, this also means that (using $(\underline{8}) \Gamma_{0}\left(y_{2}, z\right)>$ $\Gamma_{0}\left(y_{1}, z\right)$.
} 


\subsection{Sensitivity analysis}

The above results clearly depend on the choice of a poverty line. To check the sensitivity of these results, we draw $\pi_{\alpha}\left(y_{i}, z\right)$ and $\Gamma_{\alpha}\left(y_{i}, z\right)$ over poverty lines that range from 0 to 200 percent of the official US poverty threshold. For expositional simplicity, we put together all social transfers into one set referred to as "social transfers" and we do the same for the different taxes. As a result, we obtain three types of income sources: market income, social transfers, and taxes. A fourth type is the sum of the first three, and we refer to it as net income.

Two groups of countries strike out of Figures 2 and 3 in terms of market income. The first group includes United States and Canada. The second one regroups the UK, Germany and Sweden. The two ountries of the first group dominate those of the second group in terms of poverty impact since they show the highest $\pi_{\alpha}\left(y_{i}, z\right)$ whatever the value of the poverty line and for $\alpha$ equal to 0 and 1. Interestingly, Figure 3 shows that Canada dominates the US in terms of market income for the poverty deficit, albeit US market income is higher on average.

Social transfers reduce poverty significantly more in Germany and in Sweden than in the US and Canada, both in terms of poverty headcount and deficit. The UK stands at an intermediate position in that respect for any poverty standard lower than 100 percent of the US line for the headcount and even up to 200 percent of the US threshold for the poverty deficit.

Taxes impose a higher poverty burden in Sweden than in the four other countries. This is true for both values of $\alpha$ and for all of the poverty lines considered. For the poverty deficit, two other subgroups stand out. The first includes the UK and Canada, where taxes impact least on poverty, and the second includes Germany and the US, at a middle position between Sweden and the UK/Canada.

The net effect of market income, social transfers and taxes is summarized by the net income curves. Interestingly enough, no country differs markedly from the others in the final poverty outcome. With a more generous social transfer system, Sweden manages to compensate for its lower level of market income and more burdensome tax system. Germany also achieves significant net poverty reduction through its transfer system in spite of lower market income. Canada and the US compensate for a weaker poverty impact of social transfers with a significantly higher poverty impact of market income. The UK does (almost) as well as the other countries for most of the poverty lines because of a relatively large impact of social transfers and a tax system that impacts little on poverty.

The results look quite different when we turn to poverty effectiveness. Per dollar of market income, Figure 4 shows that Sweden dominates the other countries 
with respect to poverty impact. Although market income may therefore be lower on average in Sweden, it has a relatively larger poverty reduction impact. Taxes in Sweden, however, cause the greatest poverty burden relative to their average size, and social transfers are not as strikingly different from the other countries (as in Figures 2 and 3) if we normalize their impact by their size. Overall, however, in spite of an average poverty effectiveness of social transfers and a weak performance in terms of taxes, Sweden comes out on top in terms of net income poverty effectiveness. This says that per dollar of net income, poverty reduction is greatest in Sweden. This is true on Figures 4 and 5 for both values of $\alpha$ and for a wide range of poverty lines.

At the other extreme, Figures 4 and 5 show that the US almost always fares worse in terms of poverty effectiveness than the other countries - the only exception being that the US tax system is relatively good at avoiding the poor even relative to its average size. This is most striking in the case of market income and social transfers. The end result is hat net income is less poverty efficient in the US than in the other four countries.

Several of the $\Gamma_{0}\left(y_{i}, z\right)$ curves based on the headcount displayed in Figure 4 intersect, often at low poverty lines. The results are more clear-cut when on Figure 5 when the impact on the poverty deficit is considered. The UK does particularly well in that light. Only Sweden dominates it in terms of net income poverty effectiveness. The UK dominates all other countries, including Sweden, in terms of the effectiveness of social transfers, suggesting that the UK is relatively successful in the poverty targeting of those transfers. Canada is the country with the greatest success (per dollar of taxes raised) at avoiding an increase in the poverty deficit. Canada does also well at targeting transfers towards the reduction of the poverty deficit.

\section{Conclusion}

An understanding of the social benefits and costs of taxes and transfers is crucial for sound public policy. Identifying these benefits and costs is not necessarily straightforward when the taxes and transfer interact simultaneously, as they usually do. The paper proposes a methodology for doing this, focussing on the poverty alleviation effect of various income sources. The paper also distinguishes between the poverty impact and the poverty effectiveness of income sources. The poverty impact measures the absolute change in poverty caused by an income source; the poverty effectiveness normalizes that impact by the size of the income 
source.

This methodology is applied to data from five OECD countries: the United States, Germany, the United Kingdom, Canada and Sweden. We find that the poverty impact of market income in the US and Canada is higher than that in Sweden, Germany or the UK. However, more generous social transfers in Sweden, Germany and the UK lead them to roughly the net poverty outcome as in Canada and the US. Poverty impact is not, however, the same as poverty effectiveness. For instance, while social transfers in the UK are roughly half as large as those in Sweden, they are more poverty effective in the UK than in Sweden.

In brief, the findings show that US market income has the greatest poverty impact across all countries, that Swedish market income is most poverty effective, that Swedish social transfers have the greatest poverty impact, that the UK social transfers are most poverty effective (and are thus most effective at poverty targeting), and that the Canadian tax system is most successful at not increasing poverty. Conversely, the paper finds that Swedish market income has the least poverty impact, that the American distribution of market income is least poverty effective, that the US social transfers have the least poverty impact and are the least poverty effective, and that the Swedish tax system is least successful at not increasing poverty.

Note finally that in order to go beyond these findings and perform actual policy recommendations, one should also take into account possible behavioral responses to social programs that may affect market and net income in any country. Further, even if the poor do profit more from a given distribution of social transfers, this does not necessary mean that an increase in the budget devoted to those transfers would also go largely to the poor. These and other aspects would need to be carefully addressed prior to suggesting policy reforms. They would also form a natural extension of the current paper. 


\section{References}

Foster, J., J. Greer, And E. Thorbecke (1984): “A Class of Decomposable Poverty Measures," Econometrica, 52, 761-776.

HagenaArs, A., K. DE Vos, And M. Zaidi (1994): "Poverty Statistics in the Late 1980s: Research Based on Micro-data," Tech. rep., Office for Official Publications of the European Communities, Luxembourg.

Lipton, M. And M. Ravallion (1995): "Poverty and Policy," in Handbook of development economics. Volume 3B, ed. by J. Behrman and T. N. Srinivasan, Amsterdam; New York and Oxford: Elsevier Science, North Holland, 2551-2657.

Makdissi, P., Y. Therrien, AND Q. Wodon (2006): “L'Impact des transferts publics et des taxes sur la pauvreté au Canada et aux ÉtatsUnis," L'Actualité Économique, 82, 377-394.

OECD (2005): "Purchasing Power Parities," mimeo, Organization for Economic Cooperation and Development, Paris.

RAwls, J. (1971): A Theory of Justice, Cambridge: MA: Harvard University Press.

SEN, A. (1976): "Poverty: An Ordinal Approach to Measurement," Econometrica, 44, 219- 231.

Shapley, L. (1953): "A value for n-person games," in Contributions to the Theory of Games, ed. by H. W. Kuhn and A. W. Tucker, Princeton: Princeton University Press, vol. 2 of Annals of Mathematics Studies, 303-317.

Smeeding, T. (2006): "Poor People in Rich Nations: The united States in Comparative Perspective," Journal of Economic Perspectives, 20, 69-90.

ZHENG, B. (1997): “Aggregate Poverty Measures," Journal of Economic Surveys, 11, 123-62. 
Table 1: Elements involved in each composite income source

\begin{tabular}{|c|c|}
\hline \multirow{5}{*}{$\begin{array}{l}\text { Market income } \\
\text { (MI) }\end{array}$} & Cash property income \\
\hline & Gross wages and salaries \\
\hline & Private occupational pensions \\
\hline & Farm self-employment income \\
\hline & Non-farm self-employment income \\
\hline \multirow{8}{*}{$\begin{array}{l}\text { Social assistance and insurance } \\
\text { (SAI) }\end{array}$} & Sickness benefits \\
\hline & Disability benefits \\
\hline & Occupational injury and disease benefits \\
\hline & Maternity and other family leave benefits \\
\hline & Military, veterans, and war benefits \\
\hline & Other social insurance benefits \\
\hline & Social assistance cash benefits \\
\hline & Near cash benefits \\
\hline \multirow{4}{*}{$\begin{array}{l}\text { Other income sources } \\
\qquad(\mathrm{OS})\end{array}$} & In-kind earnings \\
\hline & Alimony child support \\
\hline & Regular private transfers \\
\hline & Imputed rent for owner housing \\
\hline \multirow{2}{*}{$\begin{array}{l}\text { Payroll taxes } \\
(\mathrm{PT})\end{array}$} & Mandatory employee contributions \\
\hline & Mandatory self-employment contributions \\
\hline
\end{tabular}


Table 2: Descriptive statistics (per adult equivalent adult)

\begin{tabular}{|c||c|c|c|c|c|}
\hline \hline & CA & US & UK & DE & SE \\
\hline Purchasing power parity & 1.21 & 1 & 0.641 & 0.994 & 9.31 \\
\hline $\begin{array}{c}\text { Absolute poverty line } \\
(z ; \text { in domestic currency) }\end{array}$ & 10089 & 9000 & 5769 & 8946 & 83790 \\
\hline Mean net income (ratio to $z)$ & 234.3 & 304.1 & 208.9 & 212.6 & 181.4 \\
\hline Median net income (ratio to $z)$ & 205 & 253.5 & 171.6 & 186.4 & 166 \\
\hline \hline
\end{tabular}


Table 3: Average of the different income sources per capita as a percentage of the poverty line

\begin{tabular}{|c||c|c|c|c|c|}
\hline \hline \multicolumn{1}{|c||}{} & \multicolumn{5}{c|}{$\bar{y}_{i}$} \\
\hline Market & CA & US & UK & DE & SE \\
income & $(100)$ & 225 & 150 & 153.9 & 140 \\
\hline Old-age & 13.7 & 15.3 & 10.8 & 29.15 & 21 \\
benefits & $(7.7)$ & $(6.8)$ & $(7.2)$ & $(19)$ & $(15)$ \\
\hline Child family & 2.1 & .007 & 2.5 & 4.1 & 2.7 \\
benefits & $(1.2)$ & $(.0)$ & $(1.7)$ & $(2.7)$ & $(1.9)$ \\
\hline Unemployment & 2.8 & .58 & 17 & 2.6 & 5.2 \\
benefits & $(1.6)$ & $(.26)$ & $(.1)$ & $(1.7)$ & $(3.7)$ \\
\hline Social assistance & 5.1 & 7.1 & 13.9 & 7 & 18.1 \\
\& insurance & $(2.9)$ & $(3.1)$ & $(9.3)$ & $(4.5)$ & $(12.9)$ \\
\hline \hline Total social & 23.7 & 23 & 27.4 & 42.9 & 47 \\
transfers & $(13.3)$ & $(10.2)$ & $(18.3)$ & $(27.9)$ & $(33.6)$ \\
\hline \hline Other income & .78 & 15.8 & 1.4 & 7.9 & .9 \\
sources & $(.4)$ & $(7)$ & $(1)$ & $(5.1)$ & $(.6)$ \\
\hline \hline Income & 40.2 & 41.9 & 29.8 & 28.9 & 47.8 \\
taxes & $(22.6)$ & $(18.6)$ & $(19.9)$ & $(18.8)$ & $(34.1)$ \\
\hline Payroll & 7.2 & 14 & 7.2 & 23.7 & 8.6 \\
taxes & $(4)$ & $(6.2)$ & $(4.8)$ & $(15.4)$ & $(6.1)$ \\
\hline Other direct & - & 4.7 & - & - & 4.1 \\
taxes & & $(2.1)$ & & & $(2.9)$ \\
\hline \hline Total & 47.4 & 60.6 & 37 & 52.6 & 60.5 \\
taxes (TT) & $(26.6)$ & $(26.9)$ & $(24.7)$ & $(34.2)$ & $(43.2)$ \\
\hline \hline Net income & 155 & 203 & 142.2 & 152.04 & 127.6 \\
(NI) & $(87.1)$ & $(90.2)$ & $(94.8)$ & $(98.7)$ & $(91.1)$ \\
\hline \hline
\end{tabular}

Values in parentheses are the ratio of mean income source to mean market income. Standard errors on those estimates are small and do not exceed 1.4 percent of market income, 0.9 percent of net income and 20 percent for the other income sources. 


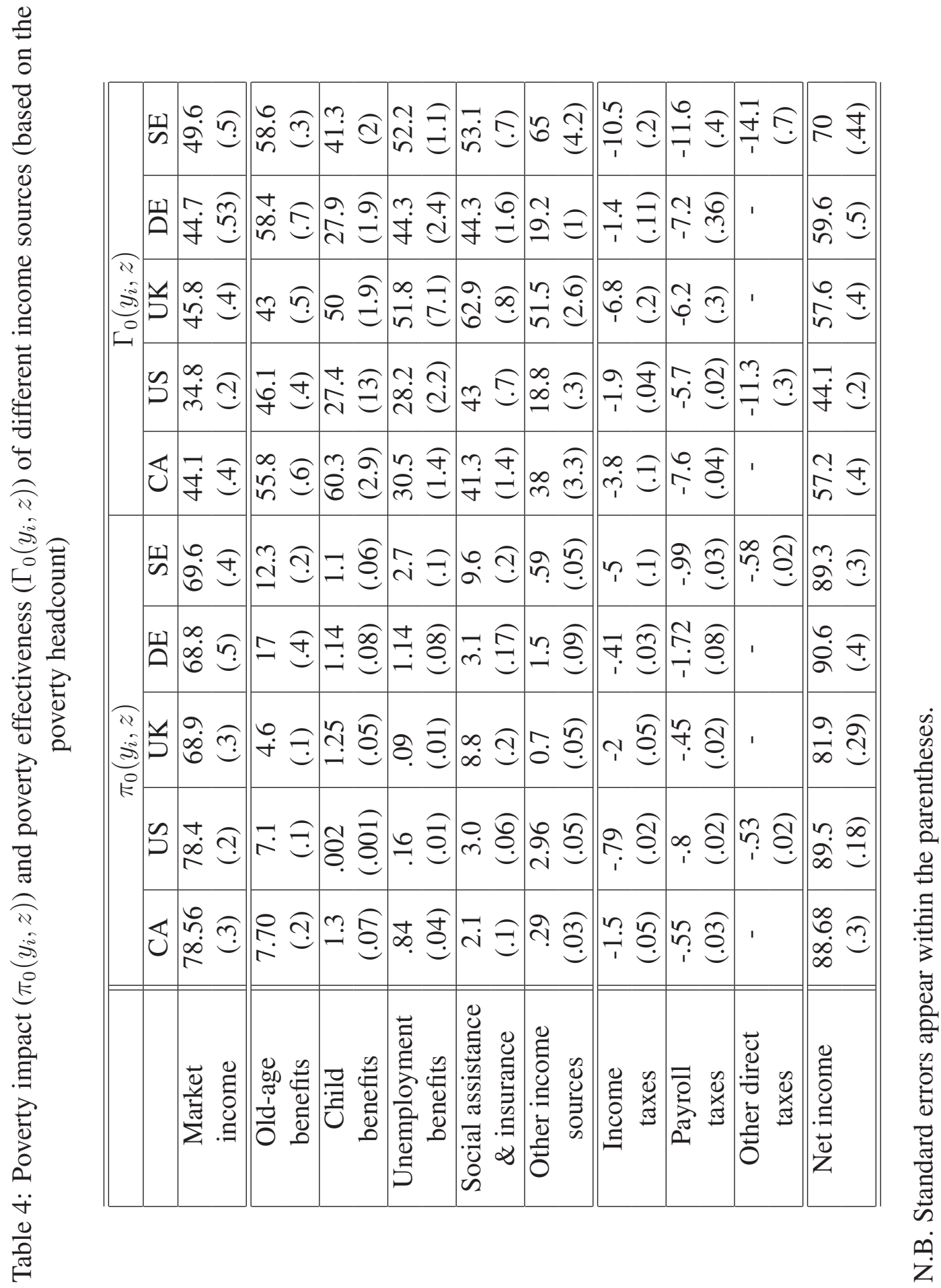




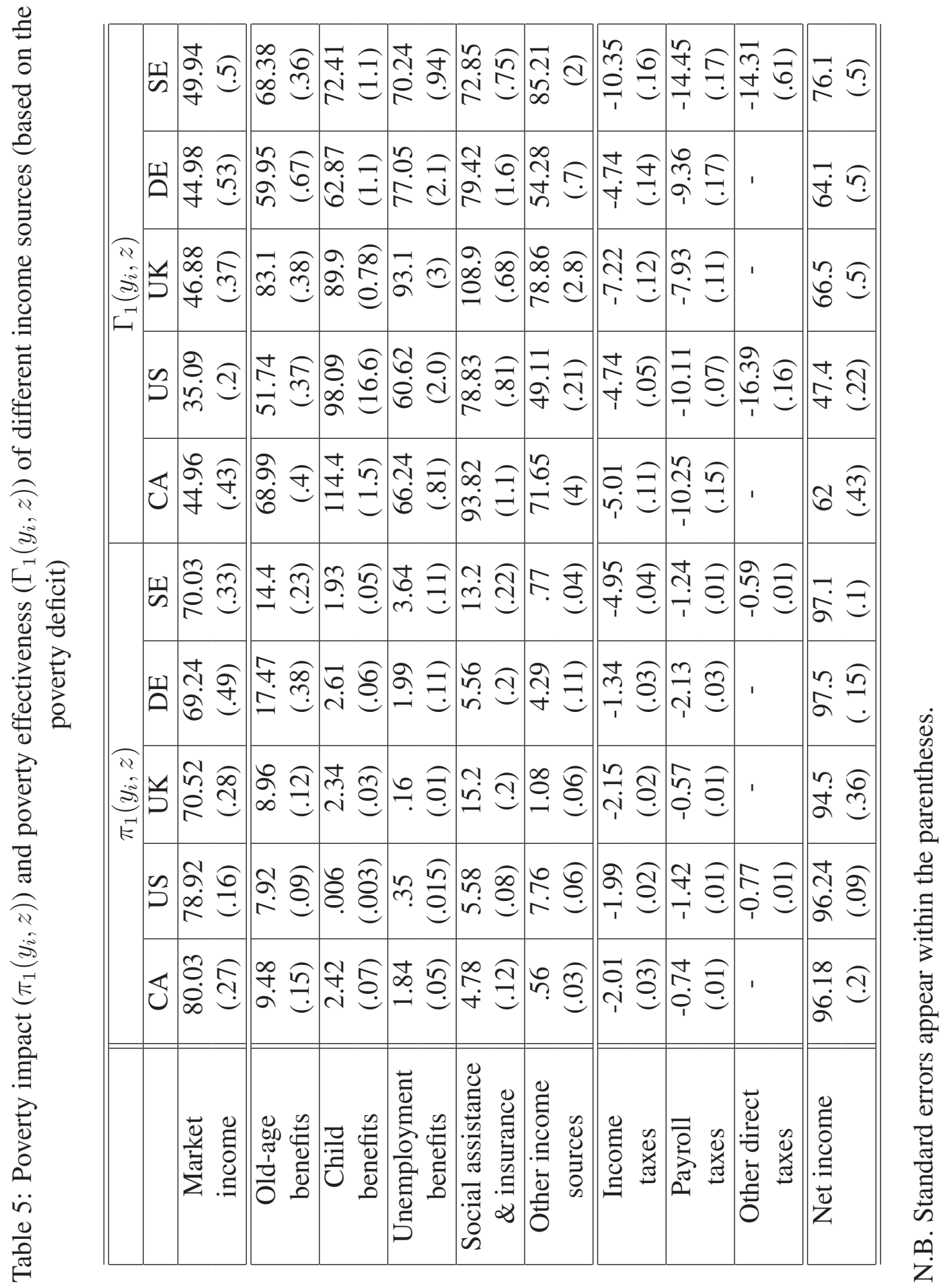




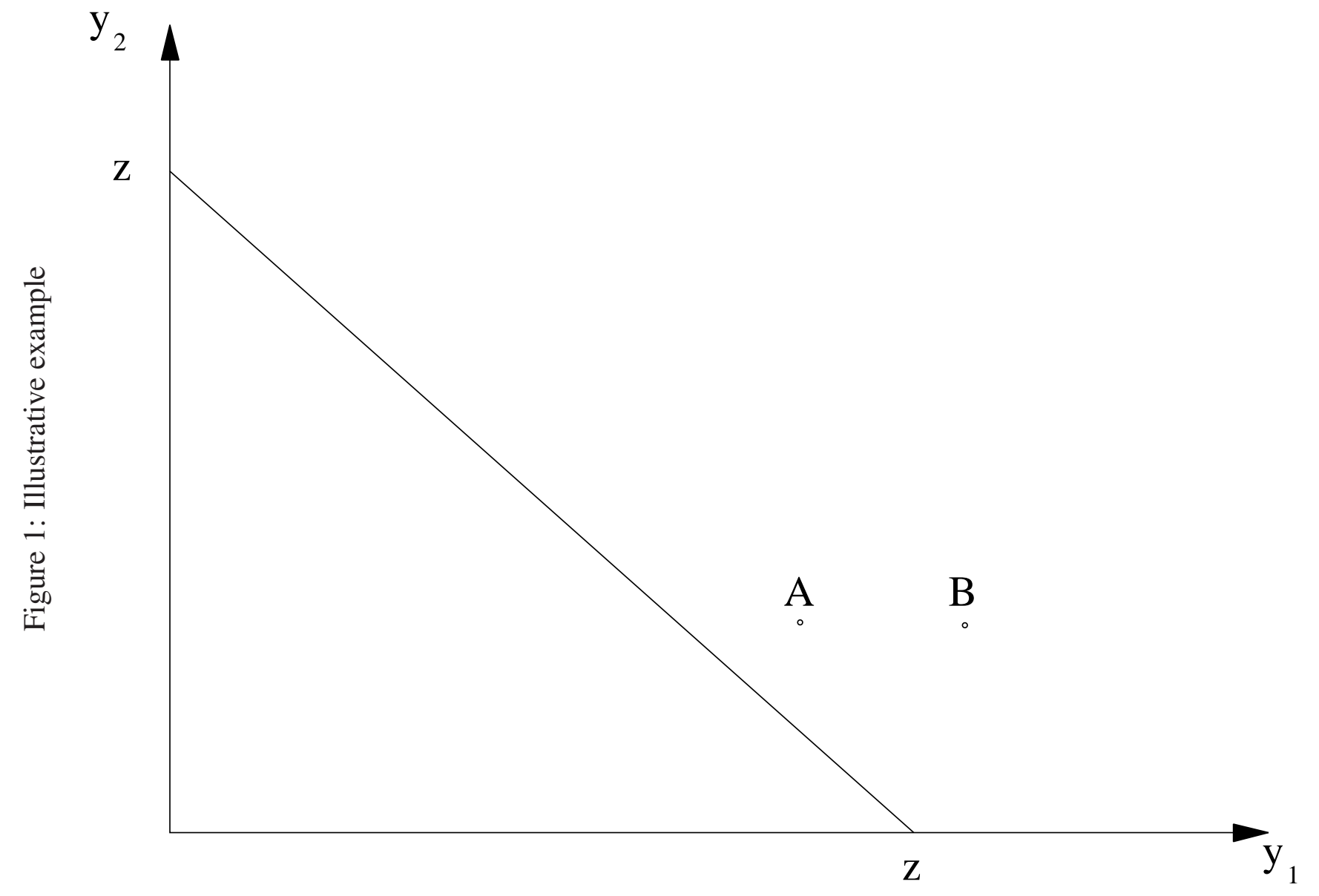




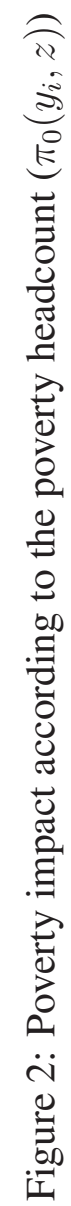
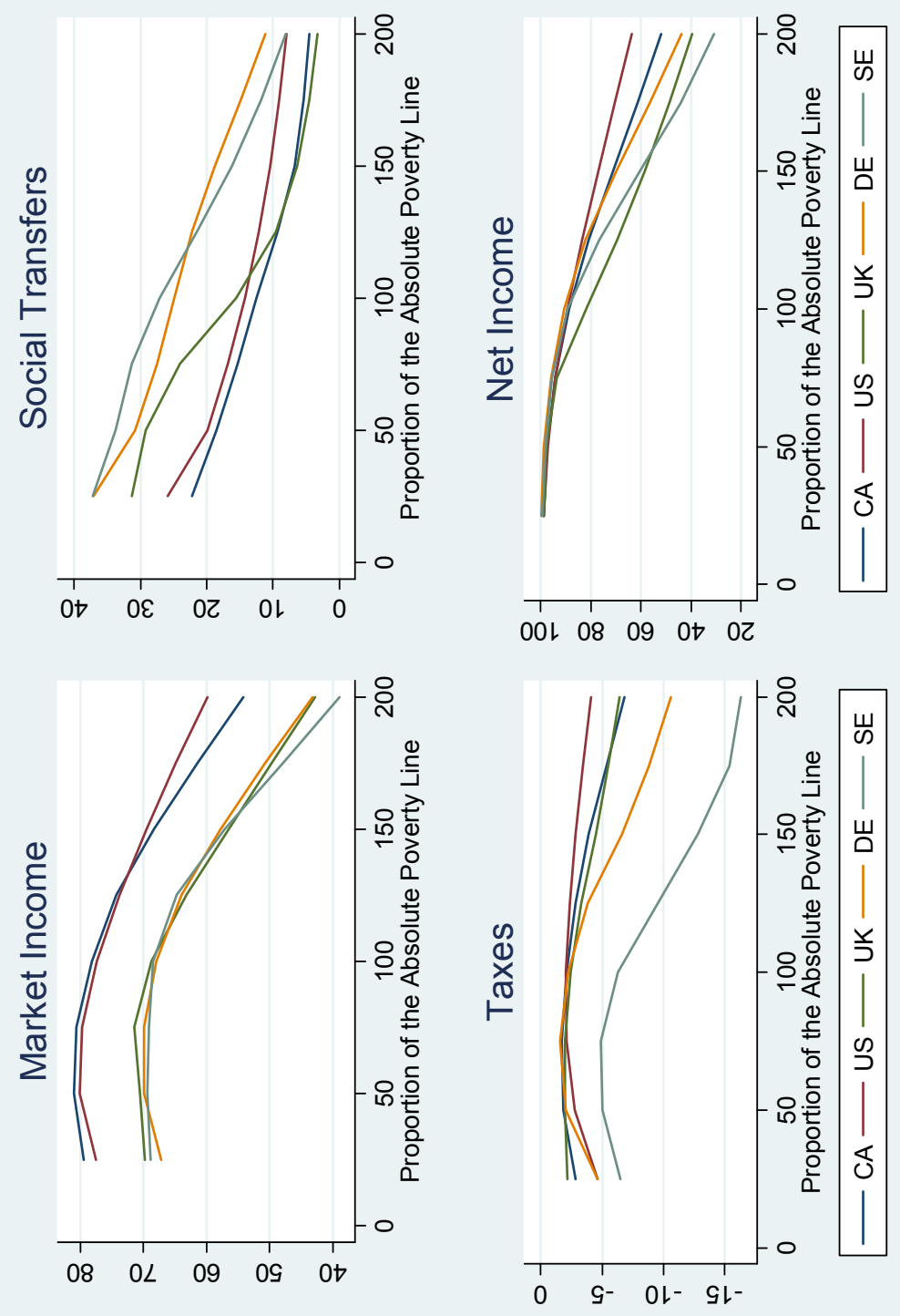


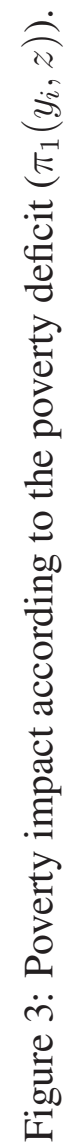
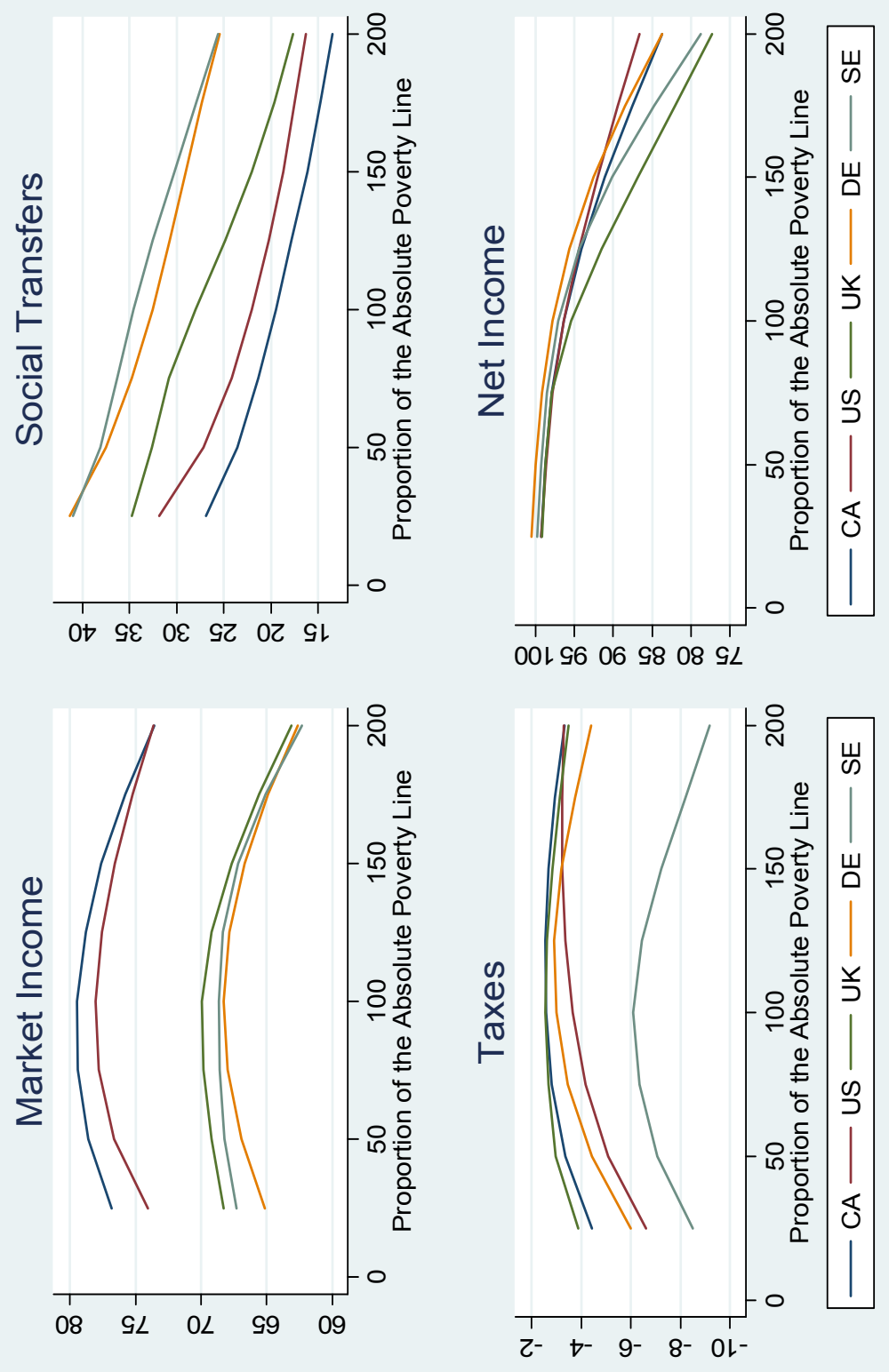


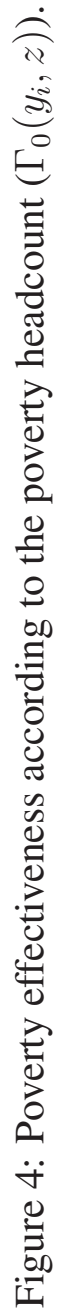
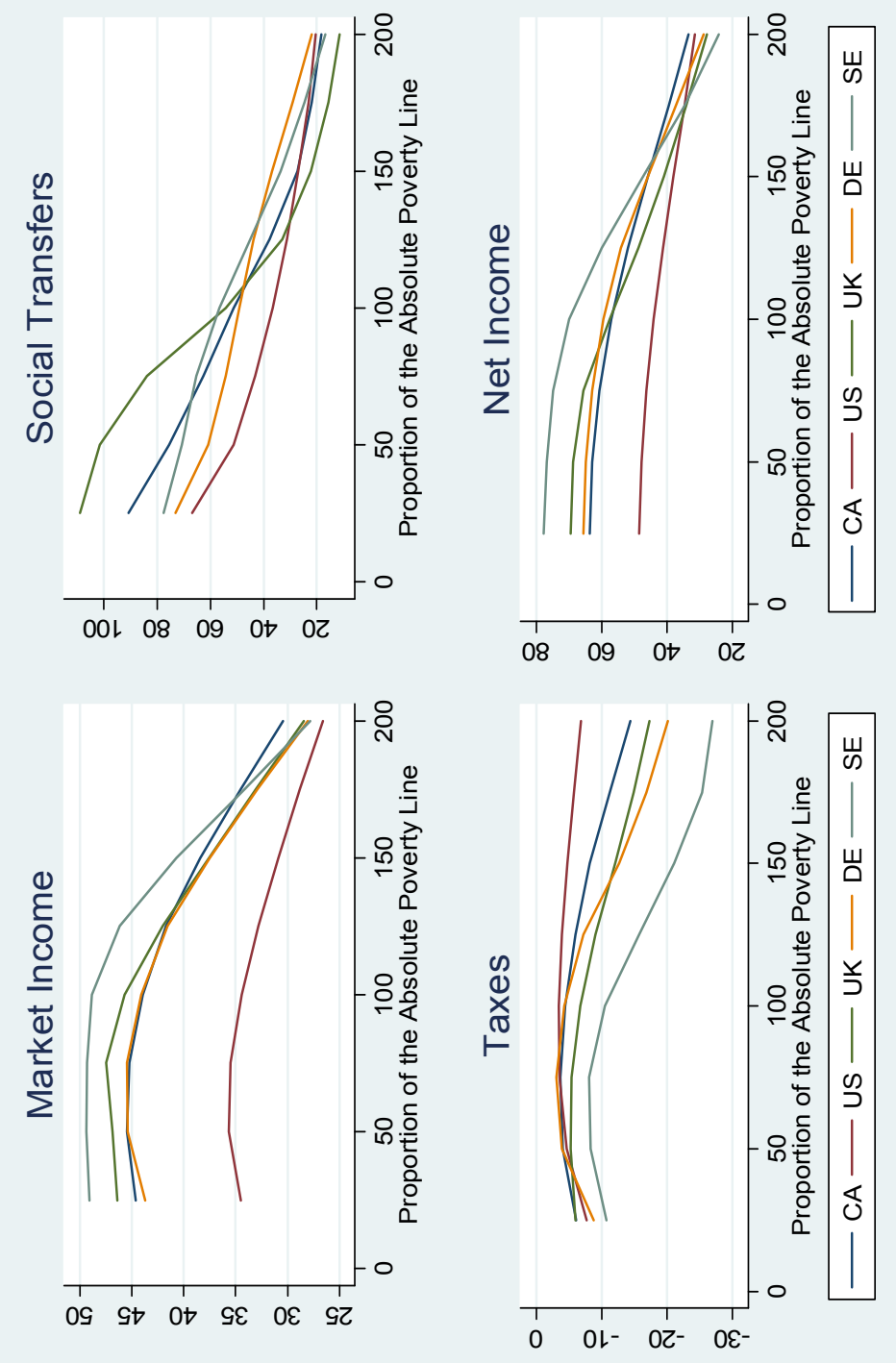


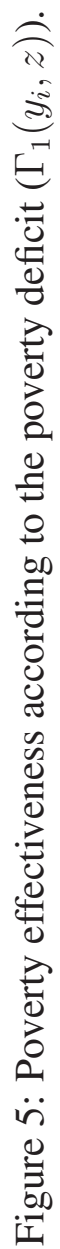
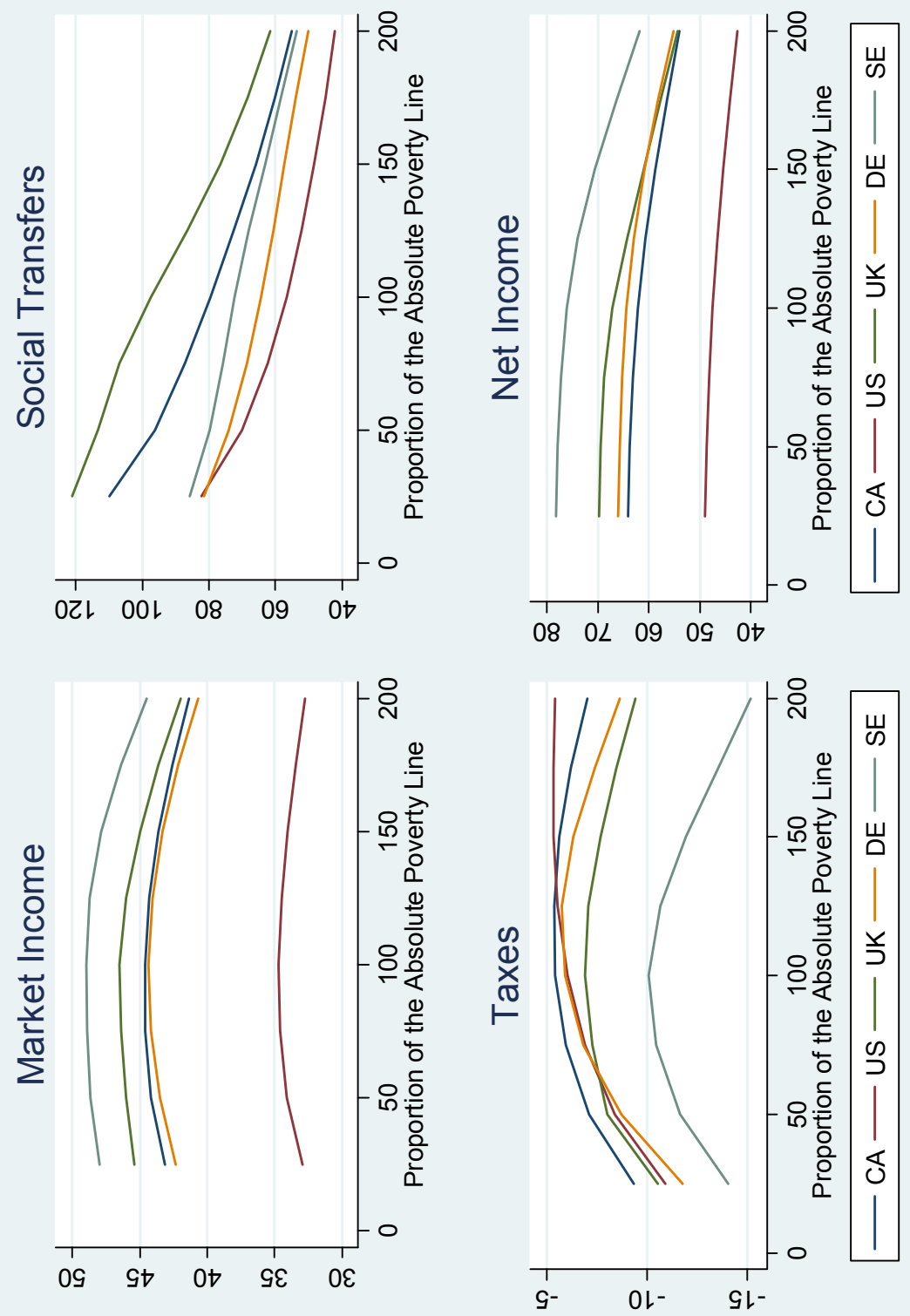